\title{
An upper-bound estimate for the accuracy of glacier volume-area scaling
}

\author{
D. Farinotti ${ }^{1,2}$ and M. Huss ${ }^{3}$ \\ ${ }^{1}$ German Research Centre for Geosciences (GFZ), Telegrafenberg, 14473 Potsdam, Germany \\ ${ }^{2}$ Laboratory of Hydraulics, Hydrology and Glaciology (VAW), ETH Zurich, 8092 Zurich, Switzerland \\ ${ }^{3}$ Department of Geosciences, University of Fribourg, 1700 Fribourg, Switzerland
}

Correspondence to: D. Farinotti (daniel.farinotti@gfz-potsdam.de)

Received: 26 April 2013 - Published in The Cryosphere Discuss.: 5 June 2013

Revised: 20 September 2013 - Accepted: 13 October 2013 - Published: 11 November 2013

\begin{abstract}
Volume-area scaling is the most popular method for estimating the ice volume of large glacier samples. Here, a series of resampling experiments based on different sets of synthetic data is presented in order to derive an upperbound estimate (i.e. a level achieved only within ideal conditions) for its accuracy. For real-world applications, a lower accuracy has to be expected. We also quantify the maximum accuracy expected when scaling is used for determining the glacier volume change, and area change of a given glacier population. A comprehensive set of measured glacier areas, volumes, area and volume changes is evaluated to investigate the impact of real-world data quality on the so-assessed accuracies. For populations larger than a few thousand glaciers, the total ice volume can be recovered within $30 \%$ if all data currently available worldwide are used for estimating the scaling parameters. Assuming no systematic bias in ice volume measurements, their uncertainty is of secondary importance. Knowing the individual areas of a glacier sample for two points in time allows recovering the corresponding ice volume change within $40 \%$ for populations larger than a few hundred glaciers, both for steady-state and transient geometries. If ice volume changes can be estimated without bias, glacier area changes derived from volume-area scaling show similar uncertainties to those of the volume changes. This paper does not aim at making a final judgement on the suitability of volume-area scaling as such, but provides the means for assessing the accuracy expected from its application.
\end{abstract}

\section{Introduction}

Directly measuring the total ice volume of a glacier is virtually impossible. Even with very detailed surveys of the ice thickness, which have recently been carried out for individual glaciers (e.g. King et al., 2009; Gabbi et al., 2012), the total ice volume needs to be recovered through interpolation of locally confined measurements. Alternatively, total volume can be inferred by using inversion techniques and information deriving from the glacier surface, such as the surface topography, flow speed, mass balance, rates of surface elevation change, or combinations of these. Recently, a number of contributions have addressed the topic, presenting a wide range of approaches with differing levels of complexity: methods that include direct ice thickness measurements have been presented by Fischer (2009), Morlighem et al. (2011), McNabb et al. (2012) and Farinotti et al. (2013); the approach by Clarke et al. (2009) is based on artificial neural networks, whilst several methods rely on principles of the ice dynamics (e.g. Raymond and Gudmundsson, 2009; Farinotti et al., 2009a; Linsbauer et al., 2012), with implementations ranging from the shallow-ice approximation $(\mathrm{Li}$ et al., 2011) to the Stokes formulation (Michel et al., 2013). Despite this wealth of approaches, many studies - especially those focusing on sea level change, mountain hydrology, and other climate change impacts - have been using, and still use, simpler approaches, mostly based on empirical relations between glacier volume and area (e.g. Van de Wal and Wild, 2001; Comeau et al., 2009; Radić and Hock, 2010; Marshall et al., 2011; Hagg et al., 2013; Grinsted, 2013). This is either due to the lack of necessary data sets, the large spatial scale 
considered, or the convenience of simpler methods. Although Huss and Farinotti (2012) recently presented the first physically based estimate for the glacier ice thickness distribution of all glaciers around the globe (besides the two ice sheets), thus providing in principle a ready-to-go estimate of the total volume of every individual glacier on Earth, volume-area scaling will certainly remain widely used in the near future and, therefore, deserves attention.

Volume-area scaling relates glacier volume $V$ (measured in $\left.\mathrm{km}^{3}\right)$ to glacier area $A\left(\mathrm{~km}^{2}\right)$ by means of the power law

$V=c \cdot A^{\gamma}$

where $c$ (units $\mathrm{km}^{(3-2 \gamma)}$ ) and $\gamma$ are two parameters to be estimated. Although Bahr et al. (1997) provided the physical basis for this relation, and its performance has already been addressed in the context of glacier volume projections (e.g. Radić et al., 2007, 2008; Bahr et al., 2009; Slangen and van de Wal, 2011), the appropriateness of volume-area scaling is currently highly debated. Recently, Adhikari and Marshall (2012) used higher-order mechanics for showing how estimated scaling parameters evolve over time if considering transient glacier states, confirming the results by Radić et al. (2007), whereas Huss and Farinotti (2012) pointed out that parameters can also vary spatially on a continental scale. On the other hand, Bahr et al. (2012) emphasized the power of scaling relations in overcoming the intrinsically illposed problem of glacier volume estimations, whilst Grinsted (2013) showed how including additional parameters in the regression between area and volume is of benefit for increasing the predicting skills of scaling relations, as shown earlier by Lüthi (2009).

In this contribution we do not enter the debate about whether a volume-area scaling relation that appropriately describes a given glacier population exists or not, but perform a series of synthetic experiments providing an upper-bound estimate (i.e. an estimate that is only reached in an ideal case, in which all assumptions are fulfilled) for the accuracy which can be expected when volume-area scaling is used for estimating (1) the total volume, (2) the total volume change, or (3) the total area change of a given glacier population. Insights are won from a series of resampling experiments performed on different sets of synthetic data for which the assumptions acting as the base of volume-area scaling are enforced a priori. The role of the accuracy and number of measurements available for estimating the scaling parameters is investigated separately. Furthermore, a comprehensive set of measured ice volumes and observed ice volume changes is used for assessing to which degree the confidence intervals derived from the synthetic experiments have to be amplified in applications with real-world data. The individual experiments are presented hereafter in different stand-alone sections in which the used data, the methods, and results are presented in succession with the aim of facilitating the reading.

\section{Using scaling for estimating total volumes}

The goal of the first experiment is to investigate the accuracy with which the total volume of a glacier population can be recovered by using volume-area scaling if a limited subset of measured values of a given size and accuracy is available for estimating the parameters of the scaling relation (Eq. 1). The upper-bound estimate for the accuracy is derived by considering a synthetic set of data for which the assumptions necessary for volume-area scaling are imposed a priori. In an application with real-world, non-synthetic data, these assumptions will not be fulfilled to the same ideal degree, and a lower accuracy thus must be expected.

\subsection{Generation of a synthetic data sample}

A sample $T$ of $n_{\text {true }}=171000$ synthetic volume and area pairs ("(V, A)-pairs"), intended to represent the global population of glaciers, is generated by assuming

$\mathrm{V}_{\text {true }}=c \cdot \mathrm{A}_{\text {true }}^{\gamma} \cdot \exp \left(\varepsilon_{\mathrm{V}}\right.$,true $)$,

where $\varepsilon \mathrm{V}$,true is a random noise term originating from a set of independent, identically distributed (i.i.d.) values that follow a normal distribution with zero mean and standard deviation $\sigma_{\mathrm{V} \text {,true }}\left(\right.$ i.e. $\varepsilon_{\mathrm{V} \text {,true }} \sim \mathcal{N}\left(0, \sigma_{\mathrm{V} \text {,true }}\right)$ i.i.d.). The area $A\left(\mathrm{~km}^{2}\right)$ is taken from the Randolph Glacier Inventory version 2.0 as released in June 2012 (Arendt et al., 2012). The subscript "true" is used since the data pairs are pretended to represent the set of true (i.e. exact but unknown) glacier volumes and areas. For the experiment, we chose $c=0.033$ and $\gamma=1.36$ (Bahr, 2011), and $\sigma_{\mathrm{V} \text {,true }}=0.3$, based on the analysis of the results by Huss and Farinotti (2012).

A corresponding set $M$ of synthetic values, simulating measured values, is then generated by adding white Gaussian noise to the true values of set $T$ according to

$\left\{\begin{array}{l}V_{\text {meas }}=V_{\text {true }} \cdot \exp \left(\varepsilon_{\mathrm{V}, \text { meas }}\right) \\ A_{\text {meas }}=A_{\text {true }} \cdot \exp \left(\varepsilon_{\mathrm{A}, \text { meas }}\right)\end{array}\right.$,

Similarly as above, $\quad \varepsilon_{\mathrm{V} \text {,meas }} \sim \mathcal{N}\left(0, \sigma_{\mathrm{V} \text {, meas }}\right), \quad$ and $\varepsilon_{\mathrm{A} \text {,meas }} \sim \mathcal{N}\left(0, \sigma_{\mathrm{A} \text {,meas }}\right)$, both i.i.d. In the following, $\sigma_{\mathrm{A} \text {,meas }}$ is fixed to 0.025 , i.e. assuming that the glacier area is known within $5 \%$ at the $95 \%$ level of confidence (e.g. Paul et al., 2013), whereas $\sigma_{\mathrm{V} \text {,meas }}$ will be varied in order to mimic scenarios for which the individual glacier volumes are known with different levels of accuracy.

Note that for the so-constructed data set, and because of the characteristics imposed upon $\varepsilon \mathrm{V}$,true in Eq. (2) in particular, the principle of maximum likelihood (Fisher, 1912) can be used for showing that a least-squares fit of the logarithmically transformed $A$ and $V$ data provides the statistically most efficient estimator for the parameters $c$ and $\gamma$. Note also that this is not in contrast to Grinsted (2013), who argued that using a least absolute deviation estimator would be "better suited for sea level rise studies, as an error in the volume of 
a large ice mass is arguably more important than an error in a small ice mass", since that statement refers to "real" data, in which normality of the residuals cannot be guaranteed a priori.

\subsection{Accuracy with which the total volume can be recovered}

Equation 3 postulates the existence of a scaling relation which describes the true volume of individual glaciers within a deviation of $\varepsilon \mathrm{V}$,meas. Let $P(P \in T)$ be a subset of $n_{\mathrm{P}}$ glaciers out of the global population $T$, as it could be the glacier population of a particular hydrological catchment, a particular mountain range, or a continent. And let $Q(Q \in M)$ be a subset of $n_{\mathrm{Q}} \leq n_{\mathrm{P}}$ glaciers for which the volume and area are known from measurements. The accuracy with which the true, unknown total volume $V_{\mathrm{P}}$ of the population $P(P \in T)$ can be recovered if the subsample $Q$ is available for estimating the parameters of the scaling relation, can be estimated through Experiment A as follows:

\section{Experiment A}

(A.1) Randomly select a sample $P$ of $n_{\mathrm{P}}(\mathrm{V}, \mathrm{A})$-pairs from $T$. This sample represents the glacier population for which the total volume shall be estimated.

(A.2) Out of $P$, randomly select a subsample of $n_{\mathrm{Q}}(\mathrm{V}, \mathrm{A})$ pairs, and consider the corresponding measured values $Q$. This sample represents a subset of the glacier population for which individual glacier volumes are known from measurements. The total volume of $Q$ is denoted with $\hat{V}_{\mathrm{Q}}$, where " "»" indicates that the value is estimated, namely through the sum of the measured volumes, which all differ by a certain amount from the true (unknown) ones.

(A.3) Estimate the parameters $c$ and $\gamma$ of the scaling relation by using the subsample $Q$ selected in (A.2). The estimate is performed by a least-squares fit of the logarithmically transformed (V, A)-data.

(A.4) Estimate the volume $\hat{V}_{\mathrm{R}}$ of the "remaining" subsample $R=Q^{C} \cap P$ of $n_{\mathrm{R}}=n_{\mathrm{P}}-n_{\mathrm{Q}}$ glaciers (i.e. that fraction of the glacier population for which no measured volumes are available; $Q^{C}$ indicating the complement of $Q$ with respect to the whole set $M$ ) by using the scaling relation (Eq. 1) and the parameters estimated in (A.3).

(A.5) Compute the difference between the estimated volume $\hat{V}_{P}=\hat{V}_{Q}+\hat{V}_{R}$ and the true volume $V_{P}$, which can be calculated from the true values.

(A.6) Repeat steps (A.1) to (A.5) 1000 times, in order to obtain an empirical confidence interval for the result in (A.5).
(A.7) Repeat the steps (A.1) to (A.6) for (a) different sizes of sample $P$ and subsamples $Q$ and $R$ (i.e. different $n_{\mathrm{P}}, n_{\mathrm{Q}}$ and $n_{\mathrm{R}}$ ), and (b) different "measurement accuracies" (i.e. different $\sigma_{\mathrm{V} \text {,meas }}$ ).

The results of this experiment are shown in Fig. 1a for an example in which the glacier population consists of $n_{\mathrm{P}}=$ 10000 individual glaciers. For this case, the total volume can be recovered within $\approx 30 \%$ at the $95 \%$ level of confidence, if a subsample of at least 200 glaciers is available for estimating the parameters of the scaling relation. Note that, in first approximation, this statement holds true independently from the uncertainty of the measured values (different lines in Fig. 1a), as long as the scatter introduced by the uncertainty in the measurements remains below the variability imposed by $\varepsilon \mathrm{V}$,true (see Eq. 2). This is the case because the measured values are assumed to deviate from the true ones by following a normal distribution with zero mean (Eq. 3), but it would not apply in the case of a systematic error in the measurements.

In the presented example, the effect of the uncertainty in the known glacier volumes becomes visible only if the subsample used for the estimation of the parameters is very small ( $<100$ glaciers) or very large ( $\gtrsim 4000$ glaciers). Whilst the first observation is not surprising, as the standard errors of the estimated parameters increase steadily with decreasing subsample size, the second observation may be unexpected at first. In this case the estimated total volume is dominated by the values known from measurements, i.e. those values that are not estimated through scaling. As the size of the subsample used for the estimation of the parameters approaches the total sample size, the accuracy with which the total volume is recovered converges to the accuracy given by the principle of Gaussian error propagation for the sum of measured values.

The deterioration in accuracy with which the total volume is recovered if the size of the subsample used for estimating the parameters drops below $\approx 50$ glaciers is very important. For a subsample of a dozen glaciers for example, the total volume can only be recovered within a factor of 2 (100\% deviation), even if the measurements of the subsample would be known exactly. Considering the scarcity of measured glacier volumes in real applications (according to Cogley, 2012, only about 280 worldwide) this clearly highlights the low level of accuracy that can be expected if scaling is applied with parameters estimated from a small set of local values. Such applications are, however, sometimes found in the literature (e.g. Liu and Sharma, 1988; Hagg et al., 2013).

On the other hand, the accuracy with which the true total volume can be recovered improves with increasing size of the considered glacier population $P$. For example, using $280(\mathrm{~V}, \mathrm{~A})$-pairs for estimating the scaling parameters, and assuming an uncertainty in measured volumes of $20 \%$ (two plausible values for the ice volume data available worldwide), allows recovering the total volume of a population of 

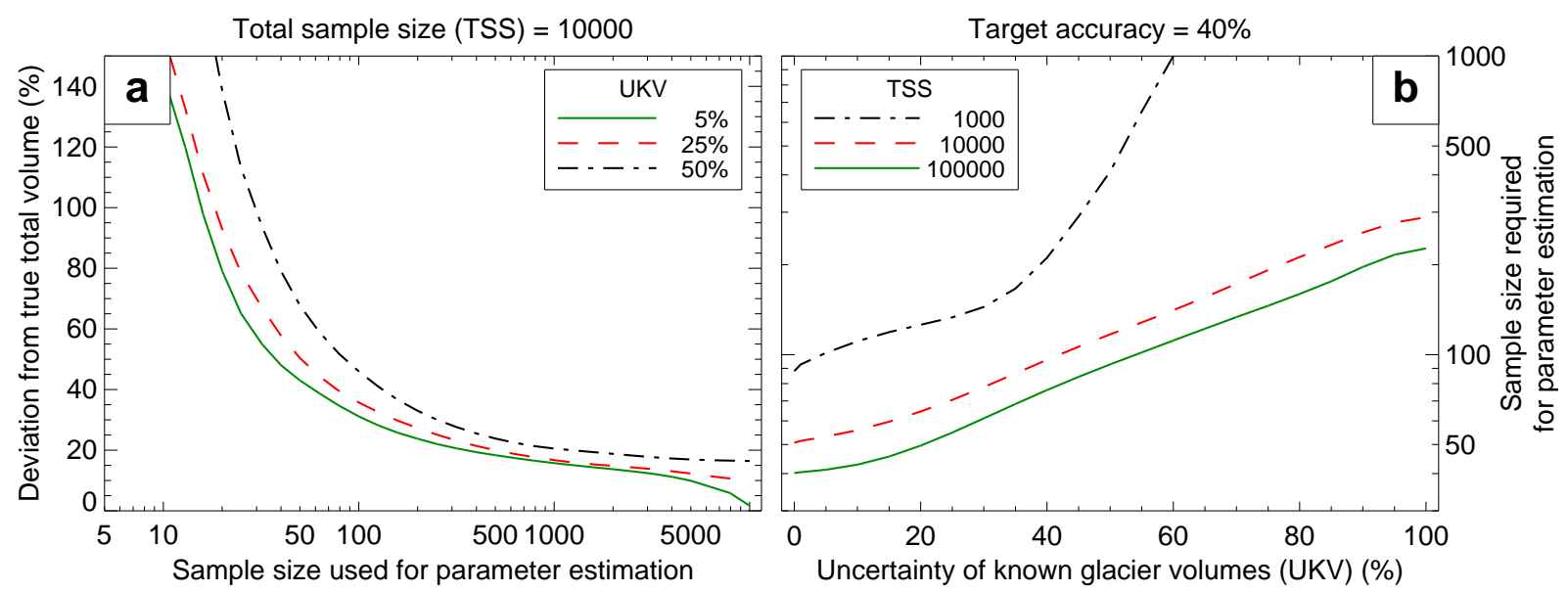

Fig. 1. (a) Accuracy (at the $95 \%$ confidence level) with which the true total volume of a population of 10000 glaciers is recovered through volume-area scaling (ordinate) if the parameters of the scaling relation are estimated by using a given number of measured (V, A)-pairs (abscissa). The different lines depict scenarios for different measurement uncertainties in glacier volume. (b) Sample size required for estimating the parameters of the scaling relation in order to recover the true total volume of a glacier population within $40 \%$ accuracy $(95 \%$ confidence level). The result is given as a function of the uncertainty in the measured volumes. The different lines show the result for different sizes of the glacier population for which the total volume is estimated.

1000,10000 and 100000 glaciers within $\approx 32, \approx 23$, and $\approx 20 \%$, respectively (not shown).

With the same assumptions for the data set used for estimating the parameters, increasing the number of glaciers to 171000 , i.e. the number of glaciers contained in the Randolph Glacier Inventory, leads to a maximal expected accuracy of $\approx 19 \%$. This indicates that the confidence interval given by Grinsted (2013) for the worldwide glacier ice volume $(0.35 \pm 0.07 \mathrm{~m}$ sea level equivalent, corresponding to an accuracy of $20 \%$ ) is conceivable as a first-order estimate. In fact, the assessment was based on a modified scaling relation that includes additional regression parameters besides glacier area, thus reducing the variance in the estimate.

\subsection{Requirements for achieving a given accuracy}

The results of the above experiment can also be used for investigating how many $(\mathrm{V}, \mathrm{A})$-pairs are required for estimating the parameters of a scaling relation such that the total ice volume of a particular glacier population is recovered within a given accuracy. Similarly as before, the answer is a function of the uncertainty associated with the measured data, and of the size of both the subsample used for calibrating the parameters and the sample for which the total volume is estimated.

Figure $1 \mathrm{~b}$ provides the results for a target accuracy of $40 \%$, i.e. the case in which the total volume of the glacier population shall be recovered within a deviation of $40 \%$ of the magnitude of the true value at the $95 \%$ confidence level. Again, the two most prominent features are (1) the relatively weak influence of the uncertainty in the known ("measured") volumes for large sample sizes, and (2) the poor performance of the scaling approach for small sample sizes. For a volume measurement uncertainty of $30 \%$, and total sample sizes of 1000 and 10000 glaciers, the required subsample size for parameter estimation is $\approx 102$ and $\approx 80$ glaciers, respectively. For a total sample size of 100000 glaciers, this number drops to $\approx 60$ glaciers. This can be explained by the fact that by increasing the sample size for which the total volume is estimated, random deviations cancel each other out even if the estimated scaling parameters are relatively poorly constrained.

The results highlight the fact that if a sufficient number of measured ice volumes are available, and scaling is applied to a sufficiently large sample of glaciers, the accuracy of the measurements itself is only of secondary importance. For example, the total volume of a glacier population of 10000 glaciers, recovered through scaling with parameters estimated from a subsample of 50 glaciers for which the volume is known exactly (ideal case), can be expected to have the same accuracy as if the parameters had been estimated with a subsample of 200 glaciers for which the individual volumes are known with an uncertainty as large as $75 \%$. Remember, however, that the assumption that leads to this result is that the deviations in the measurements are random and centered around the true values, i.e. that there are no systematic errors in the measurements.

\section{Using scaling for estimating changes in volume and area}

The second set of experiments addresses the accuracy that can be expected if volume-area scaling is used for estimating changes in glacier area and volume. In this context, two applications are found in the literature: (1) either scaling is 
applied separately to two different data sets of glacier area (usually two glacier inventories, compiled for two different points in time), and the difference in the result is interpreted as the actual volume change (e.g. Granshaw and Fountain, 2006; Moore et al., 2009; Hagg et al., 2013), or (2) a volume change between two points in time is calculated by using a mass balance model, and the scaling relation is inverted in order to update glacier area (e.g. Raper et al., 2000; Van de Wal and Wild, 2001; Radić et al., 2007, 2008; Möller and Schneider, 2010; Marshall et al., 2011; Cogley, 2011). Analysis of the second application is of particular interest since the vast majority of the projections concerning the contribution of mountain glaciers and ice caps to future sea level rise in the fifth assessment report of the Intergovernmental Panel on Climate Change is based thereupon (e.g. Slangen and van de Wal, 2011; Marzeion et al., 2012; Radić et al., 2013; Giesen and Oerlemans, 2013). In the following, the accuracy that can be expected from both applications is analyzed separately. The analyses are performed in synthetic experiments again, in order to provide idealized conditions and an upper-bound estimate for the accuracy. The case of the two points in time both referring to a steady state is addressed, as well as the transient case referring to non-steady geometries.

\subsection{Generation of a synthetic data sample}

For the following analyses, the time evolution of both area and volume needs to be known for a given set of glaciers. In order to perform the analyses based on realistic glacier geometries, a subsample of 1800 glaciers is randomly extracted from the results of Huss and Farinotti (2012). Random extraction guarantees that the distribution of glacier areas in the subsample remains unaltered with respect to the original population. Extracted glaciers have an initial area between 0.8 and $510 \mathrm{~km}^{2}$. From an ice-dynamics point of view, the selected pairs composed of a bedrock and a surface geometry are mutually consistent only within the simplified model that was used in Huss and Farinotti (2012). The individual glaciers are therefore first grown to a steady state by using the 3-D full Stokes ice-dynamics model by Jouvet et al. (2008). This is done by initializing the model with a given glacier geometry, and imposing a constant climate until a steady state is reached (see below). Climate forcing is prescribed by an altitude-dependent, annual surface mass balance distribution $b\left(\mathrm{~m} \mathrm{yr}^{-1}\right)$, computed as

$b(z)=\min \left[(z-\mathrm{ELA}) \cdot \mathrm{d} b / \mathrm{d} z, b_{\max }\right]$,

where $z$ is elevation ( $m$ a.s.l.), ELA the equilibrium line altitude (ma.s.l.), $d b / d z$ the mass balance gradient $\left(\mathrm{yr}^{-1}\right)$, and $b_{\max }$ a prescribed maximal mass balance $\left(\mathrm{m} \mathrm{yr}^{-1}\right)$ that discards unrealistically high accumulation rates. For each glacier, a mass balance gradient is randomly assigned sampling uniformly from the interval $[3,12] 10^{-3} \mathrm{yr}^{-1}$, which is the range of values determined from field observation (e.g.
Hoelzle et al., 2003). The ELA is chosen such that the given surface geometry yields an accumulation area ratio (AAR) of 0.44 , as observed in the worldwide average (e.g. Dyurgerov et al., 2009). Maximal mass balance $b_{\max }$ is set to $b\left(z_{0.95}\right)$, where $z_{0.95}$ is the 0.95 quantile of glacier elevation. Further parameters in the ice-dynamics model include the flow rate factor $A$ and the exponent $n$ for Glen's flow law (Glen, 1955), as well as a unitless sliding coefficient $C$ controlling the implemented Weertman-type sliding (Weertman, 1964). For simplicity, all three parameters are set to constant values, chosen as $A=0.06 \mathrm{bar}^{-3} \mathrm{a}^{-1}$ (corresponding to ice at a temperature of $-1{ }^{\circ} \mathrm{C}$; Cuffey and Paterson, 2010), $n=3$, and $C=0.3$ (following Jouvet et al., 2009). Glacier sliding is assumed to occur below the ELA only, whilst, according to the model formulation, all glaciers are frozen to the bedrock above that altitude. The model by Jouvet et al. (2008) has been described, validated, and successfully applied in a number of studies (e.g. Jouvet et al., 2009, 2011a, b; Farinotti, 2013). No further details are thus provided here. For additional information we refer to the mentioned publications.

Glaciers are considered to have reached steady state if, over a $50 \mathrm{yr}$ period and within the first $300 \mathrm{yr}$ of simulation, (1) fluctuations in mass balance are within $\pm 0.1 \mathrm{~m} \mathrm{yr}^{-1}$, (2) fluctuations in ice thickness are $<2.5 \%$ of the average thickness, and fluctuations in (3) glacier area and (4) glacier volume are both $<2.5 \%$. The application of these criteria leads to the selection of 1174 glaciers $(65 \%$ of the initial sample size). Estimating scaling parameters for this sample yields $c=0.030 \pm 0.001$ and $\gamma=1.34 \pm 0.02$, which is lower than the value of $\gamma=1.375$ expected from theory (Bahr et al., 1997), but in agreement with observational data (e.g. Macheret et al., 1988; Chen and Ohmura, 1990; Meier and Bahr, 1996; Bahr et al., 1997). Inspection of the scale location and normal quantile-to-quantile plots (e.g. Chambers et al., 1983) for the residuals of this scaling relation reveal that the assumptions required for applying scaling are fulfilled (not shown).

The next step consists in prescribing an altered climate, and computing a new steady state by using the same icedynamics model. This provides a glacier evolution from which simulated ice volume changes can be derived. Perturbation in climate is prescribed as an uniform rise in ELA by $100 \mathrm{~m}$, roughly corresponding to an increase in air temperature by $0.8^{\circ} \mathrm{C}$ (Oerlemans and Fortuin, 1992). The icedynamics model is then re-run for another 300 years. Out of the 1174 glaciers, $743(63 \%)$ reach a new steady state with the same conditions as above. Steady state is reached after between 22 and 273 years (median $105 \mathrm{yr}$ ). The so-obtained sample will form the new initial population $T$ for all further analyses, with the advantage that area and volume are known at any point in time for the period between the two simulated steady states. Figure 2 visualizes the described modeling steps for two randomly selected glaciers. Scaling parameters estimated for the new sample are $c=0.040 \pm 0.001$ and $\gamma=1.33 \pm 0.02$. This is in line with the previously estimated 


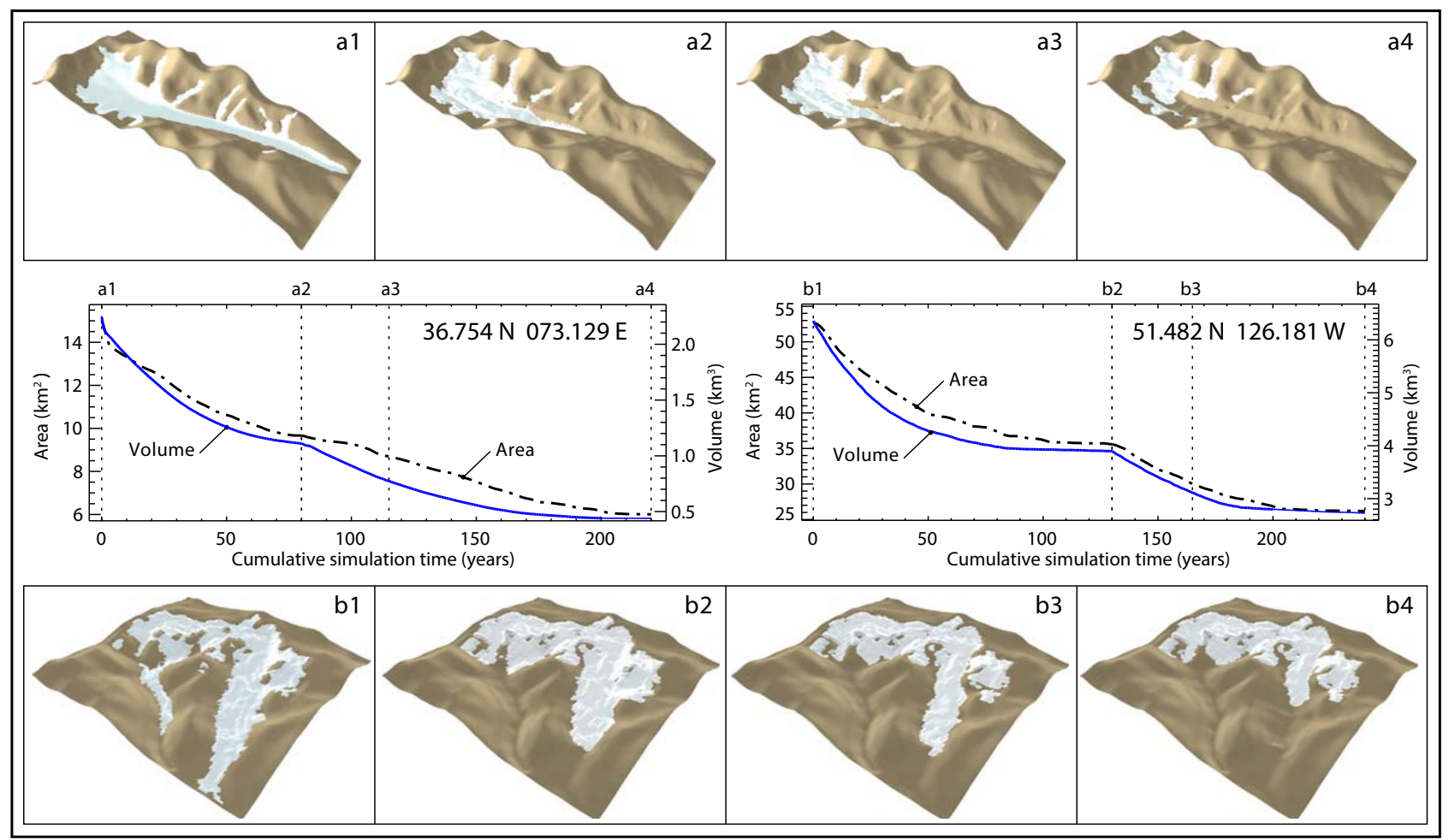

Fig. 2. Evolution of area (dash-dotted) and volume (blue) as calculated with the ice-dynamics model for two selected glaciers. "a1" and "b1" correspond to the initial glacier geometries as given by Huss and Farinotti (2012). "a2" and "b2" are the steady states reached after imposing an ELA yielding AAR $=0.44$ for the initial geometry. "a4" and "b4" are the steady-state configurations after the ELA has been increased by $100 \mathrm{~m}$, and "a3" and "b3" are a transient configuration about mid-way between the two steady states. The pronounced volume loss occurring between states " 1 " and " 2 " is the consequence of forcing present-day glacier geometries with present-day AARs, and reflects the imbalance between current glacier geometries and climate.

values since the value for $\gamma$ is unaltered, and a change in $c$ is expected because of the distribution of glacier areas consistently shifting towards lower values. Again, analysis of the residuals of the fitted relation reveals the suitability of the sample for the application of scaling.

\subsection{Accuracy of volume changes estimated from changes in area}

The accuracy with which the total volume change of a glacier population $P$ can be recovered through scaling if the area of every glacier is known for two points in time is addressed first. Similarly as before, scaling parameters are determined by assuming that a subsample $Q$ of $n_{\mathrm{Q}}$ measured (V, A)-pairs is available for calibration. Since the analyses presented so far showed that the accuracy of the measured glacier volumes only plays a minor role (Fig. 1b), $20 \%$ uncertainty in measured volumes is assumed from here on. Uncertainty in measured area is kept at the level of $5 \%$ (Paul et al., 2013).

By using the subscripts $t 1$ and $t 2$ for indicating two points in time, the experiment can be described as follows:

\section{Experiment B}

(B.1) From the total population $T$, randomly select a sample $P$ of $n_{\mathrm{P}}$ glaciers, for which the total volume change between $t 1$ and $t 2$ shall be estimated. The sample has two different states, $P_{t 1}$ and $P_{t 2}$, corresponding to the two points in time.

(B.2) Out of the combined population $P_{t 1} \cup P_{t 2}$, randomly select a subsample of $n_{\mathrm{Q}}$ glaciers, and consider the corresponding measured values $Q$ for area and volume. Subsample $Q$ will be composed of $n_{Q, t 1}(\mathrm{~V}, \mathrm{~A})$-pairs referring to time $t 1$ (subsample $M_{t 1}^{\prime}$ ), and $n_{Q, t 2}(\mathrm{~V}, \mathrm{~A})$ pairs referring to time $t 2$ (subsample $M_{t 1}^{\prime}$ ), with the condition $n_{\mathrm{Q}}=n_{Q, t 1}+n_{Q, t 2}$, and, in general, $n_{Q, t_{1}} \neq$ $n_{Q, t_{2}}$.

(B.3) Estimate the parameters $c$ and $\gamma$ of the scaling relation by using the subsample $Q$ selected in (B.2). The estimate is performed by least-squares fit of the logarithmically transformed (V, A)-data. Two cases are distinguished: in the first, one individual set of parameters is estimated for both points in time, thus assuming constant values for $c$ and $\gamma$, whereas, in the second, two 


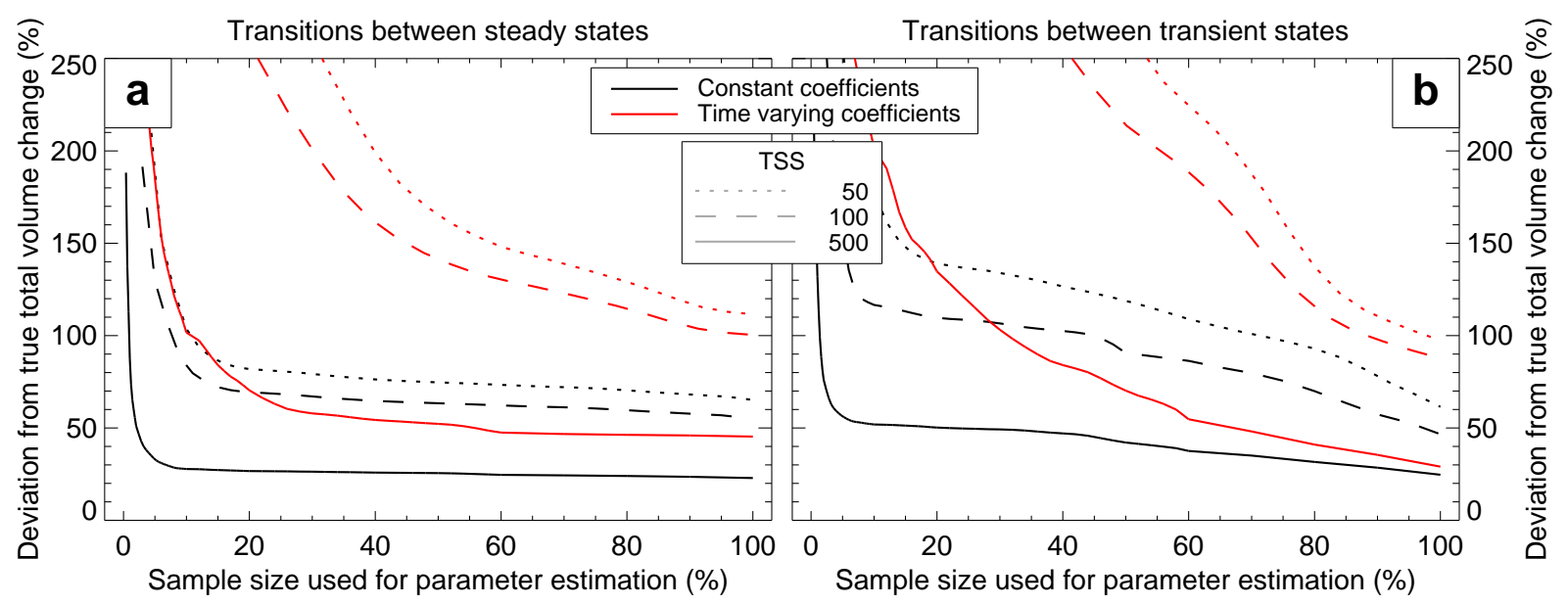

Fig. 3. Accuracy (95\% of confidence) with which the true total volume change between two points in time $t 1$ and $t 2$ can be recovered by using volume-area scaling if the area of each individual glacier is known for both $t 1$ and $t 2$. In panel (a) both $t 1$ and $t 2$ refer to steadystate geometries, whilst in panel (b) the geometries are transient. Scaling parameters are assumed to be constant (black lines) or estimated separately for $t 1$ and $t 2$ (red lines). The different line styles depict different total sample sizes (TSS) for the glacier population.

different sets of parameters are estimated for $t 1$ and $t 2$ separately.

(B.4) Estimate the volumes $\hat{V}_{\mathrm{R}, \mathrm{t} 1}$ and $\hat{V}_{\mathrm{R}, \mathrm{t} 2}$ of the remaining subsamples $R_{t 1}=M_{t 1}^{\prime C} \cap P_{t 1}$ and $R_{t 2}=M_{t 2}^{\prime C} \cap P_{t 2}$ of $n_{\mathrm{R}_{\mathrm{t} 1}}=n_{\mathrm{P}_{\mathrm{t} 1}}-n_{\mathrm{M}_{\mathrm{t} 1}^{\prime}}$ and $n_{\mathrm{R}_{\mathrm{t} 2}}=n_{\mathrm{P}_{\mathrm{t} 2}}-n_{\mathrm{M}_{\mathrm{t} 2}^{\prime}}$ glaciers, respectively, by using the scaling relation (Eq. 1) and the parameters estimated in (B.3).

(B.5) Estimate the total volume for the glacier population $P$ for the two points in time with $\hat{V}_{\mathrm{P}, t 1}=\hat{V}_{\mathrm{Q}, t 1}+\hat{V}_{\mathrm{R}, \mathrm{t} 1}$ and $\hat{V}_{\mathrm{P}, \mathrm{t} 2}=\hat{V}_{\mathrm{Q}, \mathrm{t} 2}+\hat{V}_{\mathrm{R}, \mathrm{t} 2}$, where the estimates $\hat{V}_{\mathrm{Q}, \mathrm{t} 1}$ and $\hat{V}_{\mathrm{Q}, \mathrm{t} 2}$ derive from the measured volumes, and $\hat{V}_{\mathrm{R}^{\prime}, \mathrm{t} 1}$ and $\hat{V}_{\mathrm{R}^{\prime}, \mathrm{t} 2}$ from the scaling relation.

(B.6) Estimate the total volume change between $t 1$ and $t 2$ with $\widehat{\Delta V}=\hat{V}_{\mathrm{P}, \mathrm{t} 2}-\hat{V}_{\mathrm{P}, \mathrm{t} 1}$ and compare it to the true total volume change $\Delta V_{P}$ which can be calculated from the true values.

(B.7) Repeat steps (B.2) to (B.6) 1000 times, in order to obtain an empirical confidence interval for the result in (B.6).

(B.8) Repeat steps (B.1) to (B.7) for different sizes of samples $P$ and subsamples $Q$ and $R$ (i.e. for different $n_{\mathrm{P}}$, $n_{\mathrm{Q}}$ and $\left.n_{\mathrm{R}}\right)$.

(B.9) Perform steps (B.1) to (B.8) two times: first for the case in which $t 1$ and $t 2$ both refer to a steady state ("steady-state case"), and second for the case in which neither $t 1$ nor $t 2$ refer to steady state ("transient case").

The results of this experiment are shown in Fig. 3a for the steady-state case, and in Fig. $3 \mathrm{~b}$ for the transient case. Three features are worth special notice:

(1) Estimates that assume a constant set of parameters recover the true total volume change with a higher accuracy than the estimates assuming time-varying parameters. This is true for both the steady-state and the transient case (Fig. 3a and $b$ ), although it is more prominent in the second case and if a small subset of glaciers is used for parameter estimation in particular (Fig. 3b). This observation seems to contradict earlier findings that indicate time-varying parameters (e.g. Adhikari and Marshall, 2012), but can be explained by (a) the standard errors associated with the estimated parameters, which are mainly a function of the absolute number of (V,A)-pairs available for the estimate itself, and (b) the consistency of the estimated parameters for the two points in time, which is given when assuming constant parameters, but not when these are time-varying. For a population of 100 glaciers for instance, using $50 \%$ of the sample for estimating the parameters would lead to (i) two subsamples of 50 (V, A)-pairs (one for $t 1$ and one for $t 2$ ), in the case of two different sets of parameters being estimated, or (ii) a subsample of 100 glaciers, if constant parameters were assumed. Besides the fact that a decrease in the standard errors of the estimated parameters reduces the variance in the estimated total volume as well, there is no guarantee that in the case of time-varying parameters the two sets of $50(\mathrm{~V}, \mathrm{~A})$-pairs will refer to the same subset of glaciers (which seems realistic for practical applications). This means that biases in the computed volume change are likely to be introduced through the variations in the estimated parameters. As an example, consider a glacier that does not change its geometry between two points in time: computing the glacier volume through scaling and calculating the volume change $\Delta V$ from these data will lead to $\Delta V \neq 0$ in the case of two different sets of parameters being used, and $\Delta V=0$ otherwise. Similar effects play 
a role especially if the volume changes are computed over short periods. As expected, the difference between the two assumptions (i.e. constant vs. time-variable parameters) decreases with both increasing total sample size and increasing size of the subsample used for parameter estimation. However, it remains clearly noticeable even for total sample sizes of up to 500 glaciers.

(2) In the steady-state case, increasing the set of measurements used for estimating the scaling parameters beyond a few dozens of $(\mathrm{V}, \mathrm{A})$-pairs results in a relatively weak improvement of the accuracy for the recovered total volume change (Fig. 3a). This can be explained by the fact that for transitions between steady states, the distributions of area and volume for both considered points in time fulfill the assumptions necessary for using scaling very well. As a consequence, the correct set of scaling parameters can be recovered accurately even if the subsample available for the estimate is comparatively small. Moreover, the effect of increasing standard errors with decreasing subsample size is mitigated when considering volume changes since, in this case, differences (and not absolute values) in the estimated volumes are considered. Note however that for the case of transient glacier states, the accuracy with which the true total volume change can be recovered steadily improves also if the subsample size used for the estimation of the parameters is as large as a few hundred glaciers (Fig. 3a).

(3) In general, the true total volume change can be recovered with a higher accuracy for transitions between two steady states. This is not surprising since the assumptions for using scaling are better satisfied in this case. For example, assuming constant scaling parameters and using $30 \%$ of a population of 500 glaciers for calibrating a scaling relation would allow recovering the true total volume change of that population within $\approx 30 \%$ in the steady-state case, and only within $\approx 50 \%$ in the transient case. These numbers are in line with the results of Experiment A, in which it was shown that using 150 glaciers for calibrating a scaling relation allows recovering the true total volume of a population of 500 glaciers within $\approx 40 \%$ (Fig. 1).

Summarizing the results of this experiment we conclude that, as a rule of thumb, (1) the true total volume change of large glacier populations (more than a few hundred glaciers) can be recovered through scaling with a similar accuracy as the true total volume, if a sufficient number of glaciers (more than a few dozen) are available for estimating the parameters of the relation, and (2) for practical applications, assuming constant scaling parameters increases the accuracy with which the true volume change can be recovered.

\subsection{Accuracy of updated area estimated from volume changes}

The second analysis focuses on the accuracy with which the area of a glacier population $P$ can be updated by inverting the scaling relation. This requires that the volume change be-

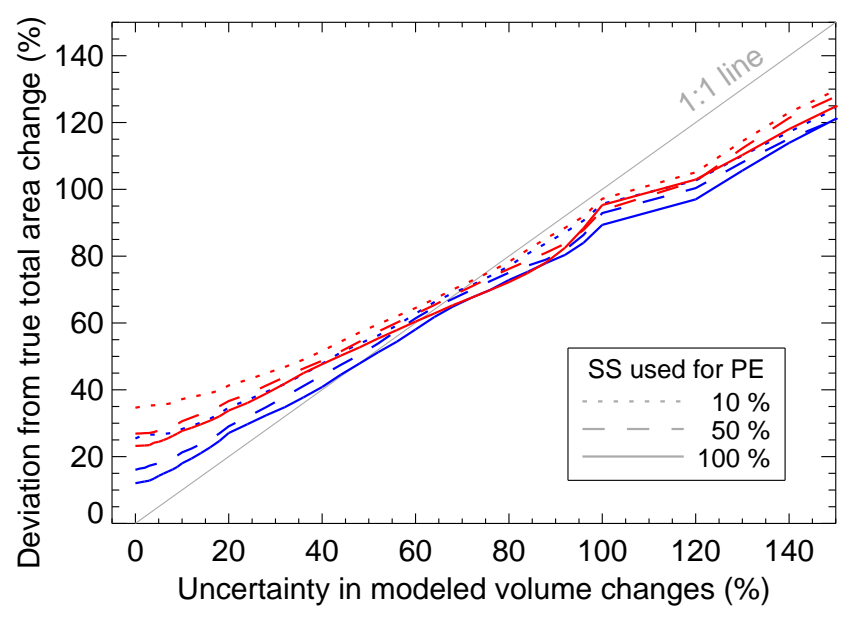

Fig. 4. Accuracy ( $95 \%$ of confidence) with which the true total area change between two points in time $t 1$ and $t 2$ can be recovered by using volume-area scaling if the volume change between $t 1$ and $t 2$ can be estimated within a given uncertainty. Blue (red) lines refer to the situation in which both $t 1$ and $t 2$ refer to steady-state (transient) geometries. The different line styles depict different subsample sizes used for parameter estimation (SS used for PE). The total glacier population is fixed to 500 glaciers. The $1: 1$ line is given as a reference.

tween the two points in time is known from a mass balance model within a given uncertainty. Similarly as before, it is assumed that a subsample $Q$ of $n_{\mathrm{Q}}(\mathrm{V}, \mathrm{A})$-pairs is available for estimating the parameters of the scaling relation. As for Experiment B, the uncertainty for measured area and volume is set to the level of $5 \%$ and $20 \%$, respectively.

Following Radić and Hock (2011) or Marzeion et al. (2012) for example, updating of glacier area is performed for each glacier individually according to

$A_{t 2}=\left[A_{t 1}^{\gamma}+\frac{\Delta V}{c}\right]^{\frac{1}{\gamma}}$,

where $\Delta V=V_{t 2}-V_{t 1}$ is the volume change between the two times $t 1$ and $t 2$, and $A_{t 1}$ and $A_{t 2}$ the corresponding glacier areas. Note that the necessary assumption for writing Eq. (5) is that the parameters of the scaling relation are constant in time. In the following, $\Delta V$ is assumed to be known from modeling only, and the estimated value $\widehat{\Delta V}$ is constructed according to

$\widehat{\Delta V}=\Delta V_{\text {true }}+\varepsilon_{\Delta \mathrm{V} \text {, modeling, }}$

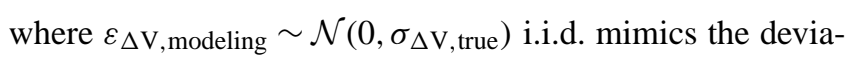
tion of the modeled value from the true one $\Delta V_{\text {true. Simi- }}$ larly as before (cf. $\varepsilon \mathrm{V}$,meas in Eq. 3) the assumption is that the deviations from the true, unknown values are centered around zero, which is a substantially stronger assumption than for measured volumes. Note, however, that the deviations are implemented differently than in the case of measured (V, A)-pairs (Eq. 3), reflecting the fact that the modeled 
volume changes may well differ from the true ones even by sign.

With the above definitions, the experiment is implemented as follows:

\section{Experiment C}

(C.1) From the total population $T$, randomly select a sample $P$ of $n_{\mathrm{P}}$ glaciers, for which the area shall be updated between the time points $t 1$ and $t 2$.

(C.2) Out of $P$, randomly select a subsample of $n_{\mathrm{Q}}(\mathrm{V}, \mathrm{A})$ pairs, and consider the corresponding measured values $Q$. The values refer to time $t$.

(C.3) Estimate the parameters $c$ and $\gamma$ of the scaling relation by using the subsample $Q$ selected in (C.2). The estimate is performed by least-squares fit of the logarithmically transformed (V, A)-data.

(C.4) Randomly assign an uncertainty to the volume changes known from modeling, i.e. randomly choose a realiza-

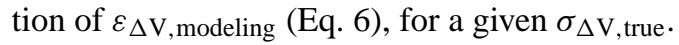

(C.5) Calculate the updated glacier area $\hat{A}_{t 2}$ for the entire population $P$ according to Eq. (5), and compare the estimated total area change $\widehat{\Delta A}=\hat{A}_{t 2}-\hat{A}_{t 1}$ to the true area change that can be computed from the known, true values.

(C.6) Repeat steps (C.2) to (C.4) 1000 times, in order to obtain an empirical confidence interval for the result in (C.5).

(C.7) Repeat steps (C.1) to (C.6) for different (a) sizes of samples $P$ and subsamples $Q$ (i.e. for different $n_{\mathrm{P}}$ and $n_{\mathrm{Q}}$ ), and (b) values of $\sigma_{\Delta \mathrm{V}}$,true, which determines the

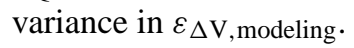

(C.8) Perform steps (C.1) to (C.7) for both the steady-state and the transient case.

The results of this experiment are shown in Fig. 4a for the steady-state case, and in Fig. 4b for the transient case.

The accuracy with which the true total area change can be recovered is almost a linear function of the uncertainty with which the corresponding volume changes are known. The size of the subsample available for estimating the scaling parameters plays a marginal role and is noticeable only if the uncertainty in the volume changes is small (below $\approx 30 \%$ ). Similarly as before, the true total area change can be recovered more precisely in the case of transitions between steadystate geometries than between transient states. Considering a population of 500 glaciers for example, if $100 \%$ (10\%) of the sample is used for estimating the scaling parameters, and if the volume changes are known exactly, the true total area change can be recovered within $10 \%(25 \%)$ between two steady states, but only within $20 \%$ (35\%) between two transient states. It is interesting to note that if the accuracy of individual volume changes is very low (uncertainty $\gtrsim 70 \%$ ), the accuracy with which the area change can be recovered is slightly better than the uncertainty with which the individual volume changes are known. If, for example, the individual volume changes are known within the magnitude of the signal itself (100\% uncertainty), the total area change can be recovered within 90 and $95 \%$ in the steady-state and transient case, respectively. This is, however, not the case when the individual volume changes are known relatively well. For example, if the individual volume changes are known exactly (with an uncertainty of $20 \%$ ) in the transient case, the true total area change can be recovered within 25-35\% (35-40\%), depending on the size of the subsample used for estimating the parameters. Thus, as a rule of thumb, one can say that by inverting the scaling relation for updating the area of a glacier population, the true total area change can be recovered with an accuracy that is comparable to the uncertainty with which the corresponding volume changes are known if this uncertainty is high, and with a significantly lower accuracy if the uncertainty in the known volume changes is low. Bear in mind, however, that the known volume changes are assumed to scatter symmetrically around the true, unknown values.

\subsection{Estimating scaling parameters from measured volume changes}

In all three experiments presented so far, the parameters of the scaling relation were derived from a given set of observed (V, A)-pairs. However, if measured volume changes are available and constant parameters are postulated (and Experiment $B$ showed that for practical application this assumption may even be advantageous), there is another potential way of estimating the parameters. Consider the equation

$V_{t 1}=c \cdot A_{t 1}^{\gamma}=V_{t 2}-\Delta V=c \cdot A_{t 2}^{\gamma}-\Delta V$,

with the same notation as used so far. Estimation of the parameters $c$ and $\gamma$ can be written as an optimization problem:

$\operatorname{argmin}_{c, \gamma}\left(\sum\left(c \cdot\left(A_{t 2}^{\gamma}-A_{t 1}^{\gamma}\right)+\Delta V\right)^{2}\right)$,

and a solution can be found by using any optimization algorithm. This alternative approach is intriguing, since it would allow estimating $c$ and $\gamma$ without requiring directly measured ice volumes, and would only be based on measurements of glacier areas and volume changes, which are much easier to acquire.

The performance of this alternative method was assessed by repeating Experiment $\mathrm{B}$ for the case in which one single set of scaling parameters is estimated for both points in time. 
The optimization problem (Eq. 8) was solved by using the algorithm by Nelder and Mead (1965) as implemented in the software package R, and a series of tests were performed in order to assess the influence of the uncertainty in the available measured volume changes.

Although promising, the alternative approach was assessed to yield substantially poorer results in comparison to the "usual way" of estimating the scaling parameters that makes use of measured (V, A)-pairs (not shown). In particular, the results were assessed to be neither robust (i.e. the estimated values did not cluster around the best estimate for small subsamples of available data) nor efficient (i.e. the confidence intervals of the estimated parameters decreased only slowly with respect to the subsample size used for parameter estimation). In practical applications, therefore, the use of this alternative approach is discouraged.

\section{Applications with real-world data}

All experiments presented so far have been performed with synthetic data, for which the preconditions for applying volume-area scaling are either imposed by definition (Experiment A) or checked a priori (Experiments B and C). For applications with real-world data, the confidence intervals estimated so far are thus expected to be systematically too narrow. For assessing by how much these confidence intervals need widening, the three experiments are repeated using measurements taken from two different data sets. The first data set was compiled by Cogley (2012), and includes measured glacier area and volume for 271 glaciers around the globe. The second data set is based on data provided by the World Glacier Monitoring Service (WGMS) and includes a total of $\approx 4000$ changes in ice thickness or ice volume reported for 214 different glaciers worldwide (WGMS, 2012). Prior to utilization, the WGMS data set was filtered in order to exclude entries that (1) have no time reference, (2) do not have information about glacier area, (3) show inconsistent information (e.g. different areas for the same point in time), (4) refer to periods shorter than 2 years, (5) only refer to a part of a glacier (e.g. a given elevation band), and (6) refer to glaciers with an area $<0.1 \mathrm{~km}^{2}$. Moreover, additional data for the Swiss Alps were retrieved from Bauder et al. (2007), Huss et al. (2008, 2010), Farinotti et al. (2009b, 2012) and Gabbi et al. (2012). This resulted in a final set of 557 measurements of volume and area changes.

Experiment A is repeated by setting the initial population $T$ to the set of 271 measured $(\mathrm{V}, \mathrm{A})$-pairs, where the true values are now given by the measurements. Uncertainty in the data is assumed to be $5 \%$ for area and $20 \%$ for volume, and is accounted for by introducing noise according to Equation 3. In each of the 1000 repetitions that are used for empirically determining the confidence intervals, a synthetic set of 271 additional values is generated according to Equation 2. This is done by setting $A$ to the measured values, and using the parameters $c$ and $\gamma$ that can be estimated from the total sample of real, measured (V, A)-pairs; i.e. $c=0.040 \pm 0.002$ and $\gamma=1.25 \pm 0.02$. Note that the estimated value for $\gamma$ is significantly lower than the value given by both the synthetic data and theory. This can be explained by the fact that the real data refer to transient geometries (e.g. Bahr et al., 1997; Adhikari and Marshall, 2012).

The two confidence intervals (one derived from the real data, one from the synthetic ones) obtained in this way for the accuracy with which the true total volume can be recovered are compared in Fig. 5a. As expected, the difference between the two decreases with increasing subsample size used for estimating the scaling parameters (since more and more volume data are assumed to be known). However, differences larger than $10 \%(20 \%)$ are assessed for subsample sizes smaller than 80 (40) glaciers. These numbers are consistent to first order with the findings by Adhikari and Marshall (2012), who analyzed a synthetic set of glaciers and found that "ca. 200 glaciers are required to produce stable solution[s] of scaling parameters". If the parameters are estimated from 20 glaciers or less, the accuracy with which the total true volume can be recovered for the real data is $45 \%$ lower than for the synthetic ones (deviations of $120 \%$ and $75 \%$, respectively). This emphasizes the importance of a sufficiently large sample for estimating the necessary parameters on the one hand, and, more importantly, the magnitude with which the accuracy in applications with real data can deviate from the ideal assumptions on the other.

For the application with real data, Experiments B and C are slightly modified. The total glacier population $T$, out of which the sample $P$ will be drawn (steps B.1 and C.1), is represented by the set of 557 measured volume and area changes. The parameters of the scaling relation, however, are determined from a subsample of given size randomly extracted from the data set of 271 real-world (V, A)-pairs (steps B.2, B.3, and C.2, C.3). Again, the assumption of constant scaling parameters is necessary. In Experiment B, steps B.4, B.5 and B. 6 are then performed analogously, with the difference that the volume of the entire population $P$ will be estimated from scaling (this is true for both points in time, $t 1$ and t2). In Experiment C, the known volume changes (step C.4) and true area changes (step C.5) are now represented by the measurements. Similarly as before, in each of the 1000 repetitions used for estimating the confidence intervals, a corresponding set of synthetic values is drawn from the population of synthetic glaciers. This is true for both the sample used for determining the scaling parameters and the sample for which changes in area or volume are estimated. For consistency with the real data, both samples are taken from geometries that refer to transient states. The experiments are repeated for different subsample sizes used for estimating the scaling parameters, whilst the size of the population $P$ is kept constant to the number of available real-world measurements (i.e. 557). Measurement uncertainty for area and volume is again assumed to be $5 \%$ and $20 \%$, respectively, 

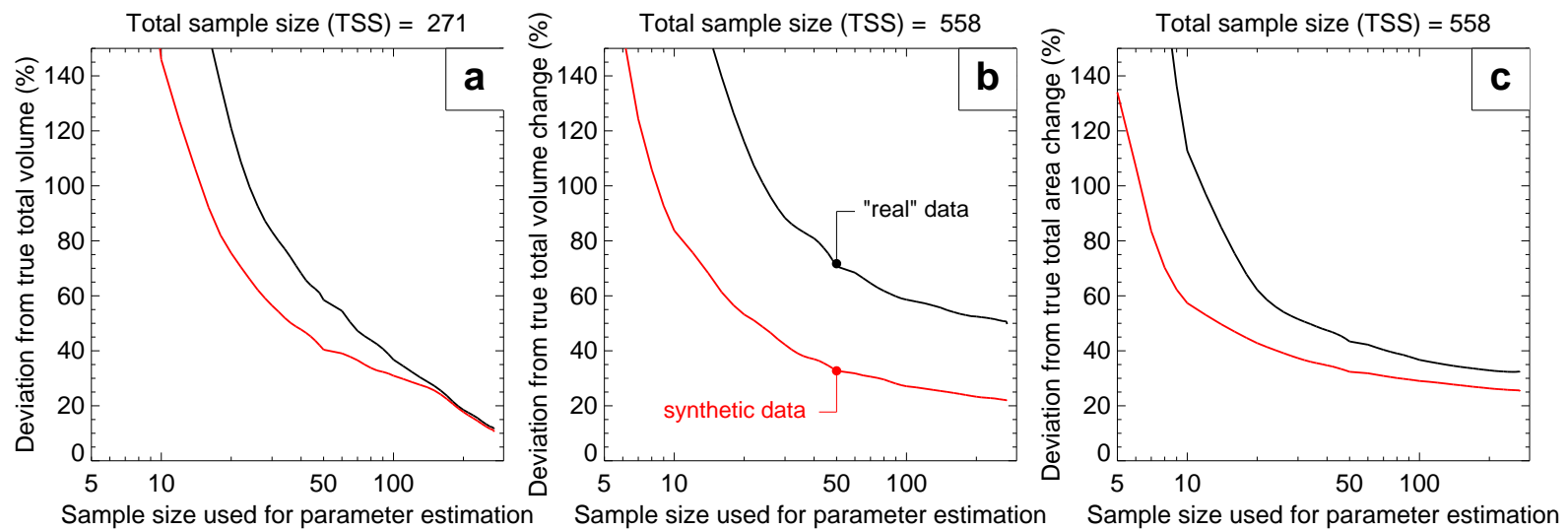

Fig. 5. Accuracy (95\% of confidence) with which the true total (a) volume, (b) volume change, and (c) area change can be recovered for a given glacier population by using volume-area scaling if the parameters of the scaling relation are estimated from a subsample of (A, V)-data of a given size. The two lines depict the cases in which the accuracy is estimated from synthetic (black) and real (red) data.

whilst uncertainty in measured volume changes is assumed to be $10 \%$.

The confidence intervals derived for the real and the synthetic data are shown in Fig. 5b for the case in which the volume change is estimated from the changes in area (Experiment B), and in Fig. 5c for the case in which the area is updated from known volume change (Experiment $\mathrm{C}$ ).

In the case of real data, the accuracy with which the true total volume change can be recovered is significantly lower compared to the synthetic data (Fig. 5b). Even if the entire set of available (V, A)-pairs is used for estimating the scaling parameters, the difference in accuracy is on the order of $30 \%$ : the true total volume can be recovered within $\approx 20 \%$ in the synthetic data case, but only within $\approx 50 \%$ in the case with real data. This figure is remarkably amplified for situations in which the scaling parameters are estimated from smaller subsamples: if $50(20)(\mathrm{V}, \mathrm{A})$-pairs are used for parameter estimation, the difference in accuracy corresponds to $\approx 40 \%(\approx 65 \%)$. The application of scaling for estimating volume changes in real applications is thus suitable only for samples with several hundreds of glaciers. Moreover, the database of measured (V, A)-pairs that is required for achieving a reasonable level of accuracy in this case needs to be extended from the "few dozen" necessary in the synthetic case with ideal conditions to "about a hundred". This may lead to questioning the suitability of this approach for applications outside the global context, such as applications at the mountain-range scale, in which measurements are rarely available for more than a dozen glaciers.

Given that a sufficiently large sample of $(\mathrm{V}, \mathrm{A})$-pairs is used for estimating the scaling parameters, the accuracy with which the true area change can be recovered for real data is reduced only marginally compared to the synthetic case (Fig. 5c). If the entire sample of (V,A)-pairs is used for parameter estimation, the true total area change can be recovered within $\approx 25 \%$ and $\approx 35 \%$ in the synthetic and the real data case, respectively. The difference increases when a smaller subsample of values is used for estimating the parameters, but the changes are less pronounced than in the case where scaling is used for estimating the volume change: if $30 \%(10 \%)$ of the available $(\mathrm{V}, \mathrm{A})$-pairs are used for parameter estimation, the difference between the application to real and synthetic data is $10 \%(15 \%)$. The use of scaling for updating the glacier area in real applications thus seems to be reasonable if (a) the application is performed for a sufficiently large set of glaciers, (b) sufficient $(\mathrm{V}, \mathrm{A})$-pairs are available for estimating the scaling parameters, and (c) the corresponding volume changes are known with a sufficient level of accuracy. In applications that aim at modeling future glacier evolution, condition (c) can be considered as the limiting factor. In fact, recall that the abovementioned numbers refer to the case in which the individual volume changes are known within $10 \%$ uncertainty, and, more importantly, that the individual values are assumed to scatter around the unknown, true values.

\section{Conclusions}

The accuracy that can be expected when using volumearea scaling for estimating the total volume, the total volume change, or the total area change of a glacier population was investigated using a series of resampling experiments. By considering different sets of synthetic data explicitly constructed in order to fulfill the assumptions that underlie volume-area scaling, the derived confidence intervals for the stated accuracies represent an upper-bound, i.e. a level of accuracy that will not be reached in applications with real data. The amount with which these accuracies need to be adjusted in applications with real-world data was assessed by considering a comprehensive compilation of measured glacier volumes, areas, and changes in area and volume. 
Based on the presented analyses, the following statements can be formulated:

1. The accuracy with which the total volume of a glacier population can be recovered is a function of both the size of the population itself and the size of the sample used for estimating the scaling parameters. Given that "a few dozen" (V, A)-pairs are available for estimating the scaling parameters, applications of scaling for populations of several hundred glaciers and more can be considered appropriate if the recovery of the true total volume within $40 \%$ (at the $95 \%$ of confidence) is considered to be a sufficient degree of accuracy. For samples larger than "a couple of thousand" glaciers, accuracies better than about $30 \%$ can be achieved if a set of $(\mathrm{V}, \mathrm{A})$-pairs having the size of all measurements available worldwide (about 280) are used for estimating the scaling parameters. This shows the limitations of using scaling relations calibrated with local data. Presupposing that no systematic measurement errors occur, the uncertainty associated with the individual $(\mathrm{V}, \mathrm{A})$-pairs only plays a marginal role. It is not possible to give one number for the decrease in accuracy that has to be expected in applications with real data. However, considering the limited amount of directly measured (V, A)-pairs, a loss in accuracy by $20 \%$ and more may occur in applications at the mountain-range scale.

2. Applying volume-area scaling for estimating the volume change of a glacier population for which the area is known for two points in time is suitable for glacier populations larger than a few hundred glaciers. The condition is that a sufficient number of glaciers (more than a few dozen) are available for estimating the scaling parameters. Assuming scaling parameters that do not vary over time is not only necessary from a practical point of view but also has a positive effect on the accuracy of the estimate. This is especially true if relatively small glacier populations and small volume changes are considered. The difference between the upper-bound accuracy derived from synthetic experiments and the accuracy that can be expected in applications with real data is more pronounced than in the case of estimated total volumes. However, if all measurements available worldwide are used for estimating the scaling parameters, total volume changes derived from scaling can be expected to be recovered within $50 \%$ and less for populations of 500 glaciers and more.

3. The accuracy with which the area of a glacier population can be updated by inverting volume-area scaling if the volume change is known, is nearly a linear function of the uncertainty in the volume change itself. If the uncertainty in the known volume changes is above $30 \%$, the total area change can be recovered only within an accuracy that is comparable to the known volume changes. For uncertainties lower than that, the accuracy of the inferred area change improves less fast than the reduction in uncertainty in the known values. Assuming that volume changes are known with an uncertainty of $10 \%$, and that a sufficient quantity of $(\mathrm{V}, \mathrm{A})$-pairs is available for estimating the scaling parameters, the total area change of a glacier population of some hundred glaciers $(\gtrsim 500)$ can be recovered within $30 \%$. This number increases only slightly in applications with real data. The necessary prerequisite, however, is that the volume changes are known without a systematic bias.

The presented analysis does not aim at making a final judgement about the suitability of volume-area scaling, but provides the means for assessing the accuracy that can be expected from a particular application.

Acknowledgements. This work benefited from financial support of the Swiss National Science Foundation, and was motivated by discussions held with Katy Unger-Shayesteh. We are indebted to Guillaume Jouvet, Gilles Steiner, and the companies Ycoor Systems SA and ALPIQ SA which made possible the use of the ice-dynamics model. We acknowledge J. Graham Cogley and the World Glacier Monitoring Service for providing measured ice volumes and volume changes, respectively. The constructive comments by Surendra Adhikari and an anonymous referee helped to improve the manuscript.

The service charges for this open access publication have been covered by the Max Planck Society.

Edited by: F. Pattyn

\section{References}

Adhikari, S. and Marshall, S.: Glacier volume-area relation for high-order mechanics and transient glacier states, Geophys. Res. Lett., 39, L16 505, doi:10.1029/2012GL052712, 2012.

Arendt, A. et al.: Randolph Glacier Inventory - A Dataset of global glacier outlines: Version 2.0, GLIMS Technical Report, National Snow and Ice Data Center, Boulder, USA, digital Media, 2012.

Bahr, D. B.: Estimation of glacier volume and volume change by scaling methods, in: Encyclopedia of snow, ice and glaciers, edited by: Singh, V., Singh, P., and Haritashya, U., Springer, 2011.

Bahr, D. B., Meier, M. F., and Peckham, S. D.: The physical basis of glacier volume-area scaling, J. Geophys. Res., 102, 2035520362, 1997.

Bahr, D. B., Dyurgerov, M., and Meier, M. F.: Sea-level rise from glaciers and ice caps: A lower bound, Geophys. Res. Lett., 36, L03501, doi:10.1029/2008GL036309, 2009.

Bahr, D.B., Pfeffer, W., and Kaser, G.: Glacier volume estimation as an ill-posed boundary value problem, The Cryosphere Discussion, 6, 5405-5420, 2012. 
Bauder, A., Funk, M., and Huss, M.: Ice volume changes of selected glaciers in the Swiss Alps since the end of the 19th century, Ann. Glaciol., 46, 145-149, 2007.

Chambers, J., Cleveland, W., Kleiner, B., and Tukey, P.: Graphical Methods for Data Analysis, Wadsworth Publishing Company, Belmont, USA, 1983.

Chen, J. and Ohmura, A.: Estimation of Alpine glacier water resources and their change since the 1870s, in: Hydrology in Mountainous Regions, edited by: Lang, H. and Musy, A., IAHS Publ. No. 193., proceedings of two Lausanne symposia, 127135,1990

Clarke, G., Berthier, E., Schoof, C., and Jarosch, A.: Neural networks applied to estimating sublacial topography and glacier volume, J. Climate, 22, 2146-2160, 2009.

Cogley, J. G.: Present and future states of Himalaya and Karakoram glaciers, Ann. Glaciol., 52, 69-73, 2011.

Cogley, J.G.: The future of the World's glaciers, in: The future of the World's climate, edited by: Henderson-Sellers, A. and McGuffie, K., chap. 8, Elsevier, 205-218, doi:10.1016/B978-0-12-3869173.00008-7, 2012.

Comeau, L., Pietroniro, A., and Demuth, M.: Glacier contribution to the North and South Saskatchewan Rivers, Hydrol. Proc., 23, 2640-2653, 2009.

Cuffey, K. and Paterson, W.: The Physics of Glaciers, Elsevier, Oxford, UK, 4th Edn., 2010.

Dyurgerov, M., Meier, M.F., and Bahr, D.B.: A new index of glacier area change: a tool for glacier monitoring, J. Glaciol., 55, 710 716, doi: 10.3189/002214309789471030, 2009.

Farinotti, D.: On the effect of climate variability on mountain glaciers - insights from a case study, J. Glaciol., 59, 992-1006, doi:10.3189/2013JoG13J080, 2013.

Farinotti, D., Huss, M., Bauder, A., Funk, M., and Truffer, M.: A method to estimate ice volume and ice thickness distribution of alpine glaciers, J. Glaciol., 55, 422-430, 2009a.

Farinotti, D., Huss, M., Bauder, A., and Funk, M.: An estimate of the glacier ice volume in the Swiss Alps, Global Planet. Change, 68, 225-231, doi:10.1016/j.gloplacha.2009.05.004, 2009b.

Farinotti, D., Usselmann, S., Huss, M., Bauder, A., and Funk, M.: Runoff evolution in the Swiss Alps: Projections for selected highalpine catchments based on ENSEMBLES scenarios, Hydrol. Proc., 26, 1909-1924, doi:10.1002/hyp.8276, 2012.

Farinotti, D., Corr, H., and Gudmundsson, G.: The ice thickness distribution of Flask Glacier, Antarctic Peninsula, determined by combining radio-echo soundings, surface velocity data, and flow modelling, Ann. Glaciol., 54, 18-24, doi:10.3189/2012AoG63A603, 2013.

Fischer, A.: Calculation of glacier volume from sparse ice-thickness data, applied to Schaufelferner, Austria, J. Glaciol., 55, 453-460, 2009.

Fisher, R.: On an absolute criterion for fitting frequency curves, Messenger of Mathematics, 41, 155-160, 1912.

Gabbi, J., Farinotti, D., Bauder, A., and Maurer, H.: Ice volume distribution and implications on runoff projections in a glacierized catchment, Hydrol. Earth Syst. Sci., 16, 4543-4556, 2012, http://www.hydrol-earth-syst-sci.net/16/4543/2012/.

Giesen, R. and Oerlemans, J.: Climate-model induced differences in the 21 st century global and regional glacier contributions to sea-level rise, Clim. Dynamics, 1-18, doi:10.1007/s00382-0131743-7, 2013
Glen, J.: The creep of polycrystalline ice, Proceedings of the Royal Society of London, Series A, 228, 519-538, 1955.

Granshaw, F. and Fountain, A.: Glacier change (1958-1998) in the North Cascades National Park Complex, Washington, USA, J. Glaciol., 52, 251-256, 2006.

Grinsted, A.: An estimate of global glacier volume, The Cryosphere, 7, 141-151, doi:10.5194/tc-7-141-2013, 2013.

Hagg, W., Mayer, C., Lambrecht, A., Kriegel, D., and Azizov, E.: Glacier changes in the Big Naryn basin, Central Tian Shan, Glob. Planet. Change, in press, doi:10.1016/j.gloplacha.2012.07.010, 2013.

Hoelzle, M., Haeberli, W., Dischl, M., and Peschk, W.: Secular glacier mass balances derived from cumulative glacier length changes, Glob. Planet. Change, 36, 295-306, 2003.

Huss, M. and Farinotti, D.: Distributed ice thickness and volume of all glaciers around the globe, J. Geophys. Res., 117, F04010, doi:10.1029/2012JF002523, 2012.

Huss, M., Farinotti, D., Bauder, A., and Funk, M.: Modelling runoff from highly glacierized alpine catchment basins in a changing climate, Hydrol. Proc., 22, 3888-3902, doi:10.1002/hyp.7055, 2008.

Huss, M., Usselmann, S., Farinotti, D., and Bauder, A.: Glacier mass balance in the south-eastern Swiss Alps since 1900 and perspectives for the future, Erdkunde, 64, 119-140, 2010.

Jouvet, G., Picasso, M., Rappaz, J., and Blatter, H.: A new algorithm to simulate the dynamics of a glacier: theory and applications, $\mathrm{J}$. Glaciol., 54, 801-811, 2008.

Jouvet, G., Huss, M., Picasso, M., Rappaz, J., and Blatter, H.: Numerical simulation of Rhonegletscher from 1874 to 2100 , Journal of Computational Physics, 228, 6426-6439, 2009.

Jouvet, G., Huss, M., Funk, M., and Blatter, H.: Modelling the retreat of Grosser Aletschgletscher, Switzerland, in a changing climate, J. Glaciol., 57, 1033-1046, 2011a.

Jouvet, G., Picasso, M., Rappaz, J., Huss, M., and Funk, M.: Modelling and numerical simulation of the dynamics of glaciers including local damage effects, Mathematical Modelling of Natural Phenomena, 6, 263-280, 2011b

King, E., Hindmarsh, R., and Stokes, C.R.: Formation of mega-scale glacial lineations observed beneath a West Antarctic ice stream, Nature Geosci., 2, 585-588, doi:10.1038/NGEO581, 2009.

Li, H., Li, Z., Zhang, M., and Li, W.: An improved method based on shallow ice approximation to calculate ice thickness along flowline and volume of mountain glaciers, J. Earth Sci., 22, 441-448, 2011.

Linsbauer, A., Paul, F., and Haeberli, W.: Modeling glacier thickness distribution and bed topography over entire mountain ranges with GlabTop: Application of a fast and robust approach., J. Geophys. Res., 117, F03007, doi:10.1029/2011JF002313, 2012.

Liu, C. and Sharma, C., eds.: Report on first expedition to glaciers and glacier lakes in the Pumqu (Arun) and Poiqu (Bhote-Sun Koshi) river basins, Xizang (Tibet), China, Lanzhou Institute of Glaciology and Geocryology (LIGG), Water and Energy Commission Secretariat (WECS) and Nepal Electricity Authority (NEA), Science Press, Beijing, 1988.

Lüthi, M. P.: Transient response of idealized glaciers to climate variations, J. Glaciol., 55, 918-930, 2009.

Macheret, Y. Y., Cherkasov, P. A., and Bobrova, L. I.: Tolschina i ob'em lednikov Djungarskogo Alatau po danniy aerora- 
diozondirovaniya, Materialy Glyatsiologicheskikh Issledovanii: Khronika, Obsuzhdeniya, 62, 59-71, 1988.

Marshall, S., White, E., Demuth, M., Bolch, T., Wheate, R., Menounos, B., Beedle, M., and Shea, J.: Glacier water resources on the eastern slopes of the Canadian Rocky Mountains, Canad. Water Res. J., 36, 109-134, 2011.

Marzeion, B., Jarosch, A., and Hofer, M.: Past and future sealevel change from the surface mass balance of glaciers, The Cryosphere, 6, 1295-1322, doi:10.5194/tc-6-1295-2012, 2012.

McNabb, R., Hock, R., O’Neel, S., Rasmussen, L., Ahn, Y., Braun, M., Conway, H., Herreid, S., Joughin, I., Pfeffer, W., Smith, B., and Truffer., M.: Using surface velocities to calculate ice thickness and bed topography: A case study at Columbia Glacier, Alaska, J. Glaciol., 58, 1151-1164, 2012.

Meier, F.M. and Bahr, D.B.: Counting glaciers: Use of scaling methods to estimate the number and size distribution of the glaciers in the world, in: Glacier, ice sheets and volcanoes: A tribute to Mark F. Meier, edited by: Colbeck, S., Cold Regions Research and Engineering Laboratory (CRREL), Hanover NH, USA, special report, 89-94, 1996.

Michel, L., Picasso, M., Farinotti, D., Funk, M., and Blatter, H.: Estimating the ice thickness of mountain glaciers with an inverse approach using surface topography and mass-balance, J. Inverse Problems, 29, 035002, doi:10.1016/j.gloplacha.2012.07.010, 2013.

Möller, M. and Schneider, C.: Calibration of glacier volume-area relations from surface extent fluctuations and application to future glacier change, J. Glaciol., 56, 33-40, 2010.

Moore, R., Fleming, S.W., Menounos, B., Wheate, R., Fountain, A., Stahl, K., Holm, K., and Jakob, M.: Glacier change in western North America: influences on hydrology, geomorphic hazards and water quality, Hydrol. Proc., 23, 42-61, doi:10.1002/hyp.7162, 2009.

Morlighem, M., Rignot, E., Seroussi, H., Larour, E., Dhia, H.B., and Aubry, D.: A mass conservation approach for mapping glacier ice thickness, Geophys. Res. Lett., 38, L19503, doi:10.1029/2011GL048659, 2011.

Nelder, J. and Mead, R.: A simplex algorithm for function minimization, Computer Journal, 7, 308-313, 1965.

Oerlemans, J. and Fortuin, J.: Sensitivity of glaciers and small ice caps to greenhause warming, Science, 258, 115-117, 1992.

Paul, F., Barrand, N., Baumann, S., Berthier, E., Bolch, T., Casey, K., Frey, H., Joshi, S., Konovalov, V., Bris, R. L., Mölg, N., Nosenko, G., Nuth, C., Pope, A., Racoviteanu, A., Rastner, P., Raup, B., Scharrer, K., Steffen, S., and Winsvold, S.: On the accuracy of glacier outlines derived from remote sensing data, Ann. Glaciol., 54, 171-182, 2013.
Radić, V. and Hock, R.: Regional and global volumes of glaciers derived from statistical upscaling of glacier inventory data, J. Geophys. Res., 115, F01010, doi:10.1029/2009JF001373, 2010.

Radić, V. and Hock, R.: Regionally differentiated contribution of mountain glaciers and ice caps to future sea-level rise, Nature Geosci., 4, 91-94, doi:10.1038/ngeo1052, 2011.

Radić, V., Hock, R., and Oerlemans, J.: Volume-area scaling vs flowline modelling in glacier volume projections, Ann. Glaciol., 46, 234-240, 2007.

Radić, V., Hock, R., and Oerlemans, J.: Analysis of scaling methods in deriving future volume evolutions of valley glaciers, J. Glaciol., 54, 601-612, 2008.

Radić, V., Bliss, A., Beedlow, A., Hock, R., Miles, E., and Cogley, J.G.: Regional and global projections of twenty-first century glacier mass changes in response to climate scenarios from global climate models, Clim. Dynam., 1-22, doi:10.1007/s00382-013-1719-7, 2013.

Raper, S., Brown, O., and Braithwaite, R.: A geometric glacier model for sea-level change calculations, J. Glaciol., 46, 357-368, 2000.

Raymond, M. J. and Gudmundsson, G. H.: Estimating basal properties of ice streams from surface measurements: a nonlinear Bayesian inverse approach applied to synthetic data, The Cryosphere, 3, 265-278, doi:10.5194/tc-3-265-2009, 2009.

Slangen, A. B. A. and van de Wal, R. S. W.: An assessment of uncertainties in using volume-area modelling for computing the twenty-first century glacier contribution to sea-level change, The Cryosphere, 5, 673-686, doi:10.5194/tc-5-673-2011, 2011.

Van de Wal, R. and Wild, M.: Modelling the response of glaciers to climate change by applying volume-area scaling in combination with a high resolution GCM, Clim. Dynam., 18, 359-366, 2001.

Weertman, J.: The theory of glacier sliding, J. Glaciol., 5, 287-303, 1964.

WGMS: Fluctuations of Glaciers 2005-2010 (Vol. X), edited by: Zemp, M., Frey, H., Gärtner-Roer, I., Nussbaumer, S. U., Hoelzle, M., Paul, F. and Haeberli, W., ICSU (WDS)/IUGG (IACS)/UNEP/UNESCO/WMO, World Glacier Monitoring Service, Zurich, Switzerland, based on database version, doi:10.5904/wgms-fog-2012-11, 2012. 